\title{
Risk factors for tube exposure as a late complication of glaucoma drainage implant surgery
}

\author{
This article was published in the following Dove Press journal: \\ Clinical Ophthalmology \\ 30 March 2016 \\ Number of times this article has been viewed
}

\author{
Meenakshi Chaku' \\ Peter A Netland ${ }^{2}$ \\ Kyoko Ishida ${ }^{3}$ \\ Douglas J Rhee ${ }^{4}$ \\ 'Department of Ophthalmology, \\ Loyola University Chicago, Maywood, \\ IL, ${ }^{2}$ Department of Ophthalmology, \\ University of Virginia School of \\ Medicine, Charlottesville, VA, USA; \\ ${ }^{3}$ Department of Ophthalmology, Toho \\ University, Tokyo, Japan; ${ }^{4}$ Department \\ of Ophthalmology and Visual Sciences, \\ Case Western Reserve University, \\ Cleveland, OH, USA
}

Purpose: The purpose of this study was to evaluate the risk factors for tube exposure after glaucoma drainage implant surgery.

Patients and methods: This was a retrospective case-controlled observational study of 64 eyes from 64 patients. Thirty-two eyes of 32 patients with tube erosion requiring surgical revision were compared with 32 matched control eyes of 32 patients. Univariate and multivariate risk factor analyses were performed.

Results: Mean age was significantly younger in the tube exposure group compared with the control group ( $48.2 \pm 28.1$ years versus $67.3 \pm 18.0$ years, respectively; $P=0.003)$. The proportion of diabetic patients $(12.5 \%)$ in the tube exposure group was significantly less $(P=0.041)$ compared with the control group (37.5\%). Comparisons of the type and position of the drainage implant were not significantly different between the two groups. The average time to tube exposure was $17.2 \pm 18.0$ months after implantation of the drainage device. In both univariate and multivariate analyses, younger age $(P=0.005$ and $P=0.027)$ and inflammation prior to tube exposure ( $P \leq 0.001$ and $P=0.004)$ were significant risk factors. Diabetes was a significant risk factor only in the univariate analysis $(P=0.027)$.

Conclusion: Younger age and inflammation were significant risk factors for tube exposure after drainage implant surgery.

Keywords: glaucoma drainage implant complications, Ahmed Glaucoma Valve, Baerveldt implant, tube erosion, pericardial patch graft

\section{Introduction}

Patch graft thinning and conjunctival erosion with exposure of the silicone tube is a complication that may occur in the late postoperative period in $2 \%-7 \%$ of eyes after glaucoma drainage device implantation. ${ }^{1-9}$ Tube exposure can lead to ocular inflammation, hypotony, poor vision, and phthisis and represents a major risk factor for the development of late endophthalmitis, with the exposed tube providing a pathway for organisms to enter the eye from the ocular surface. ${ }^{10,11}$ Various methods of treatment of exposed tubes have been described, including debridement and placement of patch graft material, with or without repositioning the tube. ${ }^{12-15}$ Sclera, dura, and pericardium patch graft materials were compared and found to have similar patch graft survival. ${ }^{16}$ Prevention of tube exposure has been attempted by varying techniques, including a long scleral tunnel, different patch graft materials, ${ }^{17-19}$ and doubling of processed pericardium allograft. ${ }^{20}$

Several mechanisms have been proposed for tube exposure, including mechanical rubbing of the conjunctiva over the tube, excessive tension of the conjunctiva over the tube, or abnormal positioning of the tube. Patch graft melting has also been observed without conjunctival erosion, suggesting a role for patch graft absorption in 
the development of tube exposure. ${ }^{21}$ Previous studies have not clearly identified the risk factors for tube exposure. The purpose of this study was to identify the risk factors for tube exposure after glaucoma drainage implant surgery.

\section{Patients and methods}

This was a retrospective, comparative study of 64 eyes, including 32 eyes with tube erosion and 32 control eyes from 64 patients. Tube erosion patients were identified from consecutive medical records of patients who had surgical revision of glaucoma drainage implants for tube exposure from two glaucoma surgeons (DJR, n=16; PAN, n=16) over a 4-year period. Patients of all ages were included in the study, with no exclusion criteria for the study. Tube erosion patients were matched with the control group, identified as the subsequent consecutive primary glaucoma drainage device implanted by the same surgeon. The study was approved by the Institutional Review Board of the University of Tennessee Health Science Center and Wills Eye Hospital and conformed to the requirements of the United States Health Insurance Portability and Privacy Act. Written informed patient consent was deemed not necessary due to the retrospective nature of this study.

All patients had glaucoma drainage device implantation prior to tube exposure, including 35 Ahmed Glaucoma Valves (New World Medical, Inc., Rancho Cucamonga, CA, USA) and 29 Baerveldt implants (Advanced Medical Optics, Inc., Santa Ana, CA, USA). Tube exposures and controls treated with the Ahmed Glaucoma Valve included eyes with Model S-2 ( $n=16$ and $n=13$, respectively), Model FP-7 ( $n=2$ and $n=2$, respectively), and Model B-1 ( $\mathrm{n}=1$ and $\mathrm{n}=1$, respectively). All patients with the Baerveldt implant were treated with the Baerveldt 350 model. Nearly all patients (61 of 64 patients, 95\%) had implants placed in the superotemporal quadrant, while the device was located in the inferonasal quadrant in one eye with tube erosion and in the inferotemporal quadrant in one eye in both groups. Irradiated donor pericardium (Tutoplast; IOP Ophthalmics, Cosa Mesa, CA, USA and New World Medical, Inc.) was the material used for the patch graft at the time of the original glaucoma drainage implant surgery in all patients.

Baseline clinical characteristics and demographic data from both the tube exposure and control groups were collected from the records. Preoperative data were from the visit prior to surgical revision of the exposed tube, and postoperative data were from the final follow-up visit after surgical revision. Steroid use and inflammation were compared using data at diagnosis of tube erosion for cases and the nearest time point after drainage device implantation in controls. Sample size of at least 30 in each group was determined from the ability to detect a $20 \%$ difference between groups with a SD of $25 \%$ (power $=0.86$ ) and the ability to detect a relative risk of 1.75 with proportion unexposed of 0.5 (power $=0.90$ ). MannWhitney $U$-tests were used to compare continuous parameters between the two groups. Chi-square and Fisher's exact tests were used for categorical variables. Cox proportional hazards regression model analysis was performed to assess the relationship between tube erosion and multiple variables. $P<0.05$ was considered as statistically significant.

\section{Results}

Eyes with exposed tubes had thinning of the allograft pericardium and erosion of the conjunctiva over the silicone tube of the glaucoma drainage implant (Figure 1), requiring surgical revision. Mean follow-up from the original glaucoma drainage implant surgery was 2.3 years in the tube exposure and control groups. The characteristics of patients in both the tube exposure and control groups are shown in Table 1 . The mean age was significantly younger $(P=0.003)$ in the patients in the tube exposure group (48.2 \pm 28.1 years) compared with the control group (67.3 \pm 17.9 years). There were no significant differences of sex, ethnicity, or lens status between the tube exposure and control groups. There was no significant difference in the number of previous surgical procedures between the tube exposure $(1.5 \pm 1.05)$ and control (1.75 \pm 0.93$)$ groups $(P=0.424)$. Significantly fewer $(P=0.041)$ diabetic patients $(12.5 \%)$ were found in the tube exposure group compared to the control group (37.5\%). History of hypertension or immune system abnormalities was not significantly different between the two groups. No significant differences were found in comparison of the type of glaucoma drainage implant used in the two groups $(P=0.451)$. The glaucoma diagnosis differed in the two groups, with a

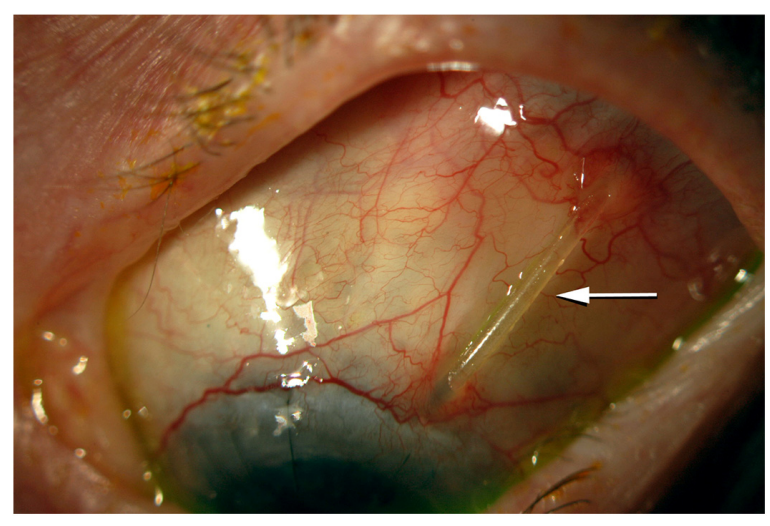

Figure I Clinical photograph of one of the eyes in this study with an exposed tube (arrow), with thinning of the allograft pericardium and erosion of the conjunctiva over the silicone tube of the glaucoma drainage device. 
Table I Characteristics of patients with tube exposure and controls

\begin{tabular}{|c|c|c|c|}
\hline Characteristics & $\begin{array}{l}\text { Tube exposure } \\
\text { eyes }(\mathrm{N}=32)\end{array}$ & $\begin{array}{l}\text { Control } \\
\text { eyes }(\mathrm{N}=32)\end{array}$ & $P$-value \\
\hline Age (years) & & & 0.003 \\
\hline Mean \pm SD & $48.2 \pm 28.1$ & $67.3 \pm 17.9$ & \\
\hline Range & $0.3-94.4$ & $20.9-91.8$ & \\
\hline Sex & & & 0.803 \\
\hline Male & 17 & 15 & \\
\hline Female & 15 & 17 & \\
\hline Ethnicity & & & 0.791 \\
\hline African-American & 10 & 11 & \\
\hline Caucasian & 19 & 19 & \\
\hline Asian & I & 2 & \\
\hline Hispanic & 2 & 0 & \\
\hline Eye & & & 0.803 \\
\hline Right & 15 & 16 & \\
\hline Left & 17 & 16 & \\
\hline Lens status & & & 0.480 \\
\hline Phakic & 7 & 8 & \\
\hline Aphakic & 3 & 6 & \\
\hline Pseudophakic & 22 & 18 & \\
\hline Hypertension & & & 0.435 \\
\hline Yes & 10 & 13 & \\
\hline No & 22 & 19 & \\
\hline Diabetes & & & 0.041 \\
\hline Yes & 4 & 12 & \\
\hline No & 28 & 20 & \\
\hline Immune system & & & 0.354 \\
\hline \multicolumn{4}{|l|}{ abnormalities } \\
\hline Yes & 4 & 1 & \\
\hline No & 28 & 31 & \\
\hline Glaucoma diagnosis ${ }^{\mathrm{a}}$ & & & 0.005 \\
\hline $\begin{array}{l}\text { Chronic open-angle } \\
\text { glaucoma }\end{array}$ & 13 & 19 & \\
\hline Pediatric glaucoma & 7 & I & \\
\hline Uveitic glaucoma & 4 & 0 & \\
\hline Neovascular glaucoma & 2 & 9 & \\
\hline Others & 6 & 3 & \\
\hline Type of implant & & & 0.451 \\
\hline Ahmed & 19 & 16 & \\
\hline Baerveldt & 13 & 16 & \\
\hline
\end{tabular}

Notes: ${ }^{2}$ Tube erosion eyes with pediatric glaucoma included three eyes with aniridia or Peters's anomaly, two eyes with Axenfeld-Rieger syndrome, and two eyes with congenital glaucoma. Controls with pediatric glaucoma included one eye with Sturge-Weber syndrome. Tube erosion eyes with other glaucoma diagnoses included one eye with chronic angle-closure glaucoma, four eyes with multimechanism glaucoma, and one eye with traumatic glaucoma. Control eyes with other glaucoma diagnoses included two eyes with chronic angle-closure glaucoma and one eye with traumatic glaucoma.

Abbreviation: SD, standard deviation.

larger number of pediatric and uveitic glaucomas in the tube erosion group compared with the control group.

Figure 2 shows the cumulative number of eyes with tube exposure over time after glaucoma drainage device implantation. Following drainage implant surgery, the average $\pm \mathrm{SD}$ time to tube exposure was $17.2 \pm 18.0$ months (median 7.9 months). All patients with tube exposure underwent surgical revision to cover the tube. Average follow-up from

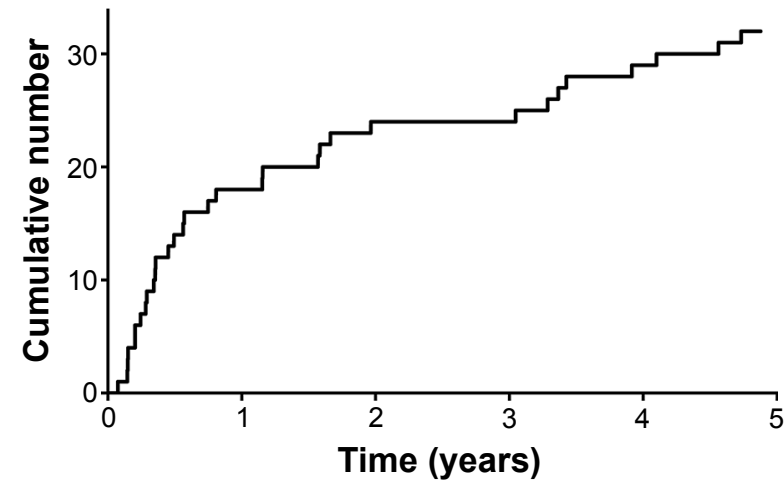

Figure 2 Cumulative number of eyes with tube exposure over time after glaucoma drainage device implantation. After drainage implant surgery, the mean \pm SD time to tube exposure was 17.2 \pm 18.0 months (median 7.9 months).

Abbreviation: SD, standard deviation.

surgical revision was 11.1 months. One of the 32 patients required multiple surgeries to cover the eroded tube. Two of the 32 patients with an eroded tube presented with an infection at the time of diagnosis of tube exposure, which required an anterior chamber injection of antibiotics.

At the time of surgical revision of tube exposure, the visual acuity in the tube exposure group ranged from 20/30 to light perception, with 17 eyes ranging from 20/300 to light perception $(\log M A R>1.0)$, ten eyes ranging from $20 / 50$ to $20 / 200$ $(0.3<\log$ MAR $\leq 1.0)$, and five eyes with $20 / 40$ or better $(\log$ MAR $\leq 0.3$ ). Mean intraocular pressure was $14.2 \pm 6.6 \mathrm{mmHg}$ (range 5-30 mmHg). At the last follow-up visit after surgical revision in the tube exposure group, final visual acuity ranged from 20/25 to no light perception in the tube exposure group. The no light perception vision was secondary to cyclitic membrane formation and hypotony. Postoperatively, 27 eyes had the same visual acuity or showed a change within only two lines from preoperative vision on the Snellen chart, and five eyes lost more than two lines of visual acuity on the Snellen chart. Postoperatively, the mean final intraocular pressure was $15.4 \pm 8.0 \mathrm{mmHg}$ (range $=7-40 \mathrm{mmHg}$ ) in the tube exposure group. This was not significantly different $(P=0.123)$ from the mean intraocular pressure prior to surgical revision. The tube exposure group was using an average of $1.0 \pm 1.4$ glaucoma medications at the final follow-up visit.

Comparisons of outcomes at the last follow-up visit are shown in Table 2. The mean intraocular pressure in the tube exposure group $(15.0 \pm 8.2 \mathrm{mmHg}$, range $=7-40 \mathrm{mmHg})$ was significantly lower $(P=0.039)$ compared with the control group $(18.6 \pm 8.9 \mathrm{mmHg}$, range $=2-40 \mathrm{mmHg})$. The average number of glaucoma medications at final follow-up was not significantly different between the two groups $(P=0.076)$, with $1.0 \pm 1.4($ range $=0-4)$ and $1.5 \pm 1.3($ range $=0-4)$ medications in the tube exposure and control groups, respectively. 
Table 2 Outcomes at last follow-up examination

\begin{tabular}{llll}
\hline Variable & Tube exposure eyes $(\mathbf{N}=\mathbf{3 2})$ & Control eyes $(\mathbf{N}=\mathbf{3 2})$ & $\mathbf{P}$-value \\
\hline Intraocular pressure $(\mathrm{mmHg})$ & & & 0.039 \\
$\quad$ Mean \pm SD & $15.0 \pm 8.2$ & $18.6 \pm 8.9$ \\
$\quad$ Range & $7-40$ & $2-40$ & 0.076 \\
Glaucoma medications & & & $1.5 \pm 1.3$ \\
$\quad$ Mean number \pm SD & $1.0 \pm 1.4$ & $0-4$ & \\
Range & $0-4$ & \\
\hline
\end{tabular}

Abbreviation: SD, standard deviation.

As shown in Table 3, the proportion of patients using steroids at diagnosis of tube exposure (78.1\%) was significantly higher $(P<0.0001)$ compared with the control group $(12.5 \%)$ at the nearest time point after drainage device implantation. The proportion of patients with inflammation prior to tube exposure $(65.6 \%)$ was significantly higher $(P<0.0001)$ compared with the control eyes at the nearest time point after glaucoma drainage implant surgery $(9.4 \%)$. Cox proportional hazards regression model analysis for risk of tube exposure is shown in Table 4. In both the univariate and multivariate analyses, younger age $(P=0.005$ and $P=0.027)$ and the presence of inflammation prior to tube exposure $(P \leq 0.001$ and $P=0.004)$ were significant risk factors for tube erosion. A history of diabetes was significant only in the univariate analysis $(P=0.027)$ and not in the multivariate analysis $(P=0.598)$. Other variables, such as sex, African-American race, hypertension, and follow-up time, were evaluated and were not statistically significant.

\section{Discussion}

Exposure of glaucoma drainage device tube is associated with potentially vision-threatening complications and requires surgical revision or removal of the device. In this study, we compared eyes with tube exposure to control eyes. Our results indicated that patients with tube exposure developed this complication, on average, at $1.43 \pm 1.50$ years after glaucoma drainage device implantation. Stewart et $\mathrm{al}^{22}$ found an overall incidence of exposure of $2.0 \% \pm 2.6 \%$ in their meta-analysis of 38 studies including 3,255 eyes. In this study, 64 eyes developed tube exposure at a rate of $0.09 \% \pm 0.14 \%$ per month. ${ }^{22}$
We found no difference in the time to erosion between eyes receiving Baerveldt versus Ahmed shunts. As both implant models utilize tubes made from medical grade silicone, this is not a surprising finding. We also found that younger age and inflammation were significant risk factors for developing exposure of the glaucoma drainage device tube.

Our average time to tube exposure from the drainage device implantation was comparable to the time to exposure in eleven eyes reported by Byun et $\mathrm{al}^{1}(1.18 \pm 1.37$ years). Unlike our study, however, their most common diagnosis was neovascular glaucoma, which was found in $45.4 \%$ of their tube exposure cases. ${ }^{1}$ Lama and Fechtner reported two cases of tube exposure in patients with primary open-angle glaucoma after glaucoma drainage implant surgery occurring 7 months and 8 months postoperatively. ${ }^{23}$ Lankaranian et a ${ }^{20}$ reported an average time to tube exposure of 9 months in five eyes (range 4-14 months), with open-angle glaucoma in three of the five eyes (60\%). In contrast, more recent studies reported a longer duration to tube exposure. Low et al ${ }^{24}$ reported an average time to exposure for the tube in 19 eyes to be $5.3 \pm 3.8$ years. Huddleston et $\mathrm{a}^{25}$ reported an average duration of $21.5 \pm 28.4$ months to tube exposure. Geffen et $\mathrm{al}^{26}$ retrospectively reviewed 158 eyes with 14 exposures (twelve of which were tube exposures) with time to exposure to be $33.2 \pm 24.5$ months.

In this study, younger age and the presence of inflammation prior to tube exposure were risk factors in both the univariate and multivariate analyses. In four patients with tube exposure evaluated by Joos et al, ${ }^{13}$ three patients had recurrent chronic inflammation. Similarly, Smith et $\mathrm{l}^{8}$ reported that

Table 3 Comparison of steroid use and inflammation

\begin{tabular}{|c|c|c|c|}
\hline Variable & Tube exposure eyes $(\mathbf{N}=32)$ & Control eyes $(\mathrm{N}=32)$ & $P$-value \\
\hline Steroid use $(\mathrm{N}, \%)^{\mathrm{a}}$ & & & $<0.0001$ \\
\hline Yes & $25(78.1)$ & $4(12.5)$ & \\
\hline No & $7(21.9)$ & $28(87.5)$ & \\
\hline Inflammation $(\mathrm{N}, \%)^{\mathrm{a}}$ & & & $<0.0001$ \\
\hline Yes & $21(65.6)$ & $3(9.4)$ & \\
\hline No & II (24.4) & $29(90.6)$ & \\
\hline
\end{tabular}

Note: aExcluding the use of routine postoperative topical steroid and inflammation during the early ( 3 months) postoperative period. 
Table 4 Outcomes of Cox proportional hazards regression model for tube exposure

\begin{tabular}{|c|c|c|c|c|}
\hline \multirow[t]{2}{*}{ Variable } & \multicolumn{2}{|l|}{ Univariate analysis } & \multicolumn{2}{|l|}{ Multivariate analysis } \\
\hline & Odds ratio $(95 \% \mathrm{Cl})$ & $P$-value & Odds ratio $(95 \% \mathrm{Cl})$ & $P$-value \\
\hline Follow-up (years) & $\mathrm{I} .006(0.690-\mathrm{I} .466)$ & 0.977 & $1.308(0.734-2.331)$ & 0.348 \\
\hline Age & $0.965(0.94 I-0.989)$ & 0.005 & $0.959(0.920-1.000)$ & 0.027 \\
\hline Female sex & $0.779(0.292-2.079)$ & 0.617 & $1.592(0.223-|| .36 \mid)$ & 0.638 \\
\hline Left eye & I.I33 (0.425-3.023) & 0.803 & $2.415(0.46 \mid-12.646)$ & 0.289 \\
\hline African-American race & $0.868(0.305-2.466)$ & 0.790 & $0.292(0.053-1.613)$ & 0.145 \\
\hline Hypertension & $0.664(0.238-1.857)$ & 0.436 & $1.274(0.226-7.202)$ & 0.783 \\
\hline Diabetes & $0.238(0.670-0.847)$ & 0.027 & $1.817(0.192-17.201)$ & 0.598 \\
\hline Ocular inflammation ${ }^{\mathrm{a}}$ & I8.455 (4.575-74.449) & $<0.0001$ & 15.180 (I.727-|33.426) & 0.004 \\
\hline
\end{tabular}

Note: a Excluding inflammation during the early (3 months) postoperative period. Abbreviation: $\mathrm{Cl}$, confidence interval.

one of the two patients who experienced tube erosion was associated with a low-grade active uveitis within 6 months of implantation of glaucoma drainage implant. Furthermore, Rachmiel et al reported tube erosion in two of 15 (13.3\%) uveitic glaucoma patients compared with one of $53(1.8 \%)$ open-angle glaucoma patients who had been treated with the Ahmed Glaucoma Valve $(P=0.120)$. Only the uveitic glaucoma patients required tube removal $(P=0.018){ }^{4}$ In contrast, Geffen et $\mathrm{al}^{26}$ did not find ocular inflammatory disease to be a significant risk factor $(P=0.33)$, although they included patients with ocular surface disease in the same category.

We found no significant difference of implant type in eyes with tube exposure compared with controls. Similarly, Lankaranian et $\mathrm{a}^{20}$ found no significant difference in the type of implant (Ahmed Glaucoma Valve or Baerveldt implant) in patients who developed tube exposure. Stewart et $\mathrm{al}^{22}$ also found no significant difference between the type of implant used and exposure rate in their meta-analysis. Several studies have shown, however, that the location of the implant may be significant. Pakravan et al found more significant complications including exposure with inferior-placed Ahmed Glaucoma Valve implants (25\%) compared to those placed superiorly (5.2\%) in their study of 106 eyes followed for an average of $10.58 \pm 6.75$ months. ${ }^{27}$ Levinson et $\mathrm{al}^{28}$ also found inferior implants exposed more frequently at $15.6 \%$ compared to superior placed implants at $6.3 \%(P=0.2761)$. Trubnik et a ${ }^{29}$ retrospectively evaluated 28 eyes $(8.3 \%)$ with tube erosion in 339 eyes treated with glaucoma drainage implants but found no significant relationship between location and erosion. However, they state that fewer tubes were placed in inferior-located positions in their study. ${ }^{29}$

The type of patch graft used to cover the tube has been studied and the exposure rates after implantation have shown to be quite variable. Smith et $\mathrm{al}^{8}$ reported a $4.3 \%$ exposure rate in 23 eyes covered with donor sclera (ethanol preserved), a $5.6 \%$ exposure rate in 18 eyes covered with dura (Tutoplast), and a $0 \%$ exposure rate in 23 eyes covered with pericardium; however, these differences were not statistically significant. Lankaranian et a ${ }^{20}$ found $16 \%$ exposure rate with single thickness processed pericardium in 31 eyes significantly compared to $0 \%$ of tubes in 59 eyes covered with double thickness processed pericardium in their study $(P=0.0002)$. Lawrence and Netland ${ }^{30}$ found no erosions of gamma-irradiated cornea (VisionGraft; Tissue Banks International, Baltimore, MD, USA) in a small pilot study with limited follow-up. However, in a larger group of patients with longer follow-up, Ekici et a ${ }^{31}$ reported a 1.8\% exposure rate of tubes in 169 eyes covered with VisionGraft gamma-irradiated cornea. In contrast, Levinson et $\mathrm{a}^{28}$ found that tubes covered with donor cornea $(9.2 \%)$ and pericardium (7.9\%) exposed more often than scleral patch grafts $(0.5 \%$, $P=0.72$ ). Authors of this study suggested that the higher rate of exposure in the corneal patch graft group was related to the more frequent use of this type of patch graft with inferiorly placed tubes, which have been shown to expose more often. ${ }^{28}$ Trubnik et al, ${ }^{29}$ however, found no significant difference of tube erosion with different patch graft materials.

Byun et al $^{1}$ found previous ocular surgery as a risk factor for tube exposure; however, Geffen et $\mathrm{a}^{26}$ found no significant risk of tube erosion with previous glaucoma procedures. In these studies, age and diabetes were not risk factors for tube exposure. ${ }^{1,26}$ In our study, fewer patients with exposed tubes had diabetes compared with controls, suggesting that diabetes was not a risk factor for exposure of drainage implant tubes. Other ocular risk factors, including previous ocular trauma and postoperative use of corticosteroids for exposure, were evaluated by Geffen et al, ${ }^{26}$ but none were found to be significant. Only mean preoperative number of glaucoma hypotensive medications was found to be a significant risk factor in the tube exposure group $(P=0.01)$ in their study. ${ }^{26}$ Huddleston et al ${ }^{25}$ also found a correlation between higher number of preoperative medications and exposure. 
In contrast, Trubnik et $\mathrm{al}^{29}$ found no significant risk of tube exposure associated with preoperative medications, but that concomitant surgical procedures were a significant risk factor for exposure. We found no significant difference in the number of previous surgical procedures in patients with exposed tubes compared with controls, although we did not evaluate subgroups of cataract surgery or other procedures because of the small number of patients in the study.

A limitation of many of the previous studies on tube exposure is the small number of subjects. Limitations of this study also include relatively small sample size as well as variation in surgeon technique and bias. Nonetheless, we identified younger age and inflammation as risk factors for tube erosion. The association of inflammation with tube exposure here and in other studies suggests possible involvement of immune mechanisms in the etiology of tube exposure and possible prevention strategies with improved modulation of the immune response.

\section{Disclosure}

Dr Netland and the University of Virginia receive research support for unrelated studies from PTC Therapeutics (South Plainfield, NJ, USA) and New World Medical (Rancho Cucamonga, CA, USA). The authors report no other conflicts of interest in this work. The authors have no proprietary interest in this material.

\section{References}

1. Byun YS, Lee NY, Park CK. Risk factors of implant exposure outside the conjunctiva after Ahmed Glaucoma Valve implantation. Jpn J Ophthalmol. 2009;53:114-119.

2. Huang MC, Netland PA, Coleman AL, Siegner SW, Moster MR, Hill RA. Intermediate-term clinical experience with the Ahmed Glaucoma Valve implant. Am J Ophthalmol. 1999;127:27-33.

3. Wishart PK, Choudhary A, Wong D. Ahmed Glaucoma Valves in refractory glaucoma: a 7-year audit. Br J Ophthalmol. 2010;94:1174-1179.

4. Rachmiel R, Trope GE, Buys YM, Flanagan JG, Chipman ML. Ahmed Glaucoma Valve implantation in uveitic glaucoma versus open-angle glaucoma patients. Can J Ophthalmol. 2008;43:462-467.

5. Mills RP, Reynolds A, Emond MJ, Barlow WE, Leen MM. Long-term Survival of Molteno glaucoma drainage devices. Ophthalmology. 1996; 103:299-305.

6. Gil-Carrasco F, Salinas-VanOrman E, Recillas-Gispert C, Paczka JA, Gilbert ME, Arellanes-García L. Ahmed Valve implant for uncontrolled uveitic glaucoma. Ocul Immunol Inflamm. 1998;6:27-37.

7. Vuori ML. Molteno aqueous shunt as a primary surgical intervention for uveitic glaucoma: long-term results. Acta Ophthalmol. 2010; 88:33-36.

8. Smith MF, Doyle JW, Tierney JW. A comparison of glaucoma drainage implant tube coverage. J Glaucoma. 2002;11:143-147.

9. Siegner SW, Netland PA, Urban RC, et al. Clinical experience with the Baerveldt glaucoma drainage implant. Ophthalmology. 1995;102: 1298-1307.

10. Al-Torbak AA, Al-Shahwan S, Al-Jadaan I, Al-Hommadi A, Edward DP. Endophthalmitis associated with the Ahmed Glaucoma Valve implant. Br J Ophthalmol. 2005;89:454-458.
11. Gedde SJ, Scott IU, Tabandeh H, et al. Late endophthalmitis associated with glaucoma drainage implants. Ophthalmology. 2001;108: 1323-1327.

12. Ainsworth G, Rotchford A, Dua HS, King AJ. A novel use of amniotic membrane in the management of tube exposure following glaucoma tube shunt surgery. Br J Ophthalmol. 2006;90:417-419.

13. Joos KM, Laviña AM, Tawansy KA, Agarwal A. Posterior repositioning of glaucoma implants for anterior segment complications. Ophthalmology. 2001;108:279-284.

14. Rootman DB, Trope GE, Rootman DS. Glaucoma aqueous drainage device erosion repair with buccalmucous membrane grafts. J Glaucoma. 2009; 18:618-622.

15. Merrill KD, Suhr AW, Lim MC. Long-term success in the correction of exposed glaucoma drainage tubes with a tube extender. $\mathrm{Am}$ J Ophthalmol. 2007;144:136-137.

16. Raviv T, Greenfield DS, Liebmann JM, Sidoti PA, Ishikawa H, Ritch R. Pericardial patch grafts in glaucoma implant surgery. J Glaucoma. 1998; 7:27-32.

17. Ollila M, Falck A, Airaksinen PJ. Placing the Molteno implant in a long scleral tunnel to prevent postoperative tube exposure. Acta Ophthalmol Scand. 2005;83:302-305.

18. Gutiérrez-Díaz E, Montero-Rodríguez M, Mencía-Gutiérrez E, Cabello A, Monescillo J. Long-term persistence of fascia lata patch graft in glaucoma drainage device surgery. Eur J Ophthalmol. 2005;15: 412-414.

19. Tanji TM, Lundy DC, Minckler DS, Heuer DK, Varma R. Fascia lata patch graft in glaucoma tube surgery. Ophthalmology. 1996;103: 1309-1312.

20. Lankaranian D, Reis R, Henderer JD, Choe S, Moster MR. Comparison of single thickness and double thickness processed pericardium patch graft in glaucoma drainage device surgery. J Glaucoma. 2008;17: 48-51.

21. Heuer DK, Budenz D, Coleman A. Aqueous shunt tube erosion. J Glaucoma. 2001;10:493-496.

22. Stewart WC, Kristoffersen CJ, Demos CM, Fsadni MG, Stewart JA. Incidence of conjunctival exposure following drainage device implantation in patients with glaucoma. Eur J Ophthalmol. 2010;20:124-130.

23. Lama PJ, Fechtner RD. Tube erosion following insertion of a glaucoma drainage device with a pericardial patch graft. Arch Ophthalmol. 1999; 117:1243-1244

24. Low SA, Rootman DB, Rootman DS, Trope GE. Repair of eroded glaucoma drainage devices: mid-term outcomes. J Glaucoma. 2012; 21:619-622.

25. Huddleston SM, Feldman RM, Budenz DL, et al. Aqueous shunt exposure: a retrospective review of repair outcome. J Glaucoma. 2013; 22:433-438

26. Geffen N, Buys YM, Smith M, et al. Conjunctival complications related to Ahmed Glaucoma Valve insertion. J Glaucoma. 2014;23: 109-114.

27. Pakravan M, Yazdani S, Shahabi C, Yaseri M. Superior versus inferior Ahmed Glaucoma Valve implantation. Ophthalmology. 2009;116: 208-213.

28. Levinson JD, Giangiacomo AL, Beck AL, et al. Glaucoma drainage devices: risk of exposure and infection. Am J Ophthlamol. 2015;160: 516-521.

29. Trubnik V, Moster MR, Chia T, et al. Evaluation of risk factors for glaucoma drainage device-related erosions: a retrospective case-control study. J Glaucoma. 2015;24:498-502.

30. Lawrence SD, Netland PA. Gamma-irradiated cornea allograft for glaucoma surgery. J Glaucoma. 2013;22:355-357.

31. Ekici F, Moster MR, Cvintal V, Hu WD, Waisbourd M. Tube shunt coverage with gamma-irradiated cornea allograft (VisionGraft). Clin Ophthalmol. 2015;9:751-755. 


\section{Publish your work in this journal}

Clinical Ophthalmology is an international, peer-reviewed journal covering all subspecialties within ophthalmology. Key topics include: Optometry; Visual science; Pharmacology and drug therapy in eye diseases; Basic Sciences; Primary and Secondary eye care; Patien Safety and Quality of Care Improvements. This journal is indexed on Submit your manuscript here: http://www.dovepress.com/clinical-ophthalmology-journal

\section{Dovepress}

PubMed Central and CAS, and is the official journal of The Society of Clinical Ophthalmology (SCO). The manuscript management system is completely online and includes a very quick and fair peer-review system, which is all easy to use. Visit http://www.dovepress.com/ testimonials.php to read real quotes from published authors. 